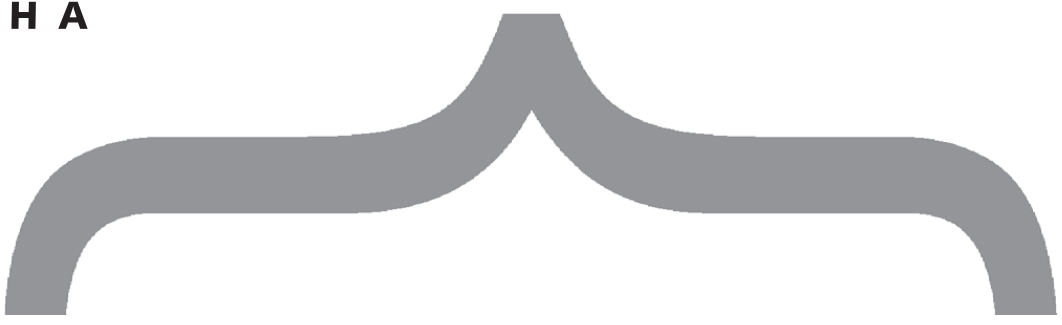

\title{
O Brasil e o capital-imperialismo, teoría e história por Virginia Fontes
}

\author{
Rita Andrea Meoño Molina*
}

En un osado recorrido teórico e histórico de 384 páginas, Virginia Fontes nos sumerge - con la autoridad intelectual que le caracteriza - en una densa y provocativa reflexión sobre las transformaciones radicales ocurridas en las últimas décadas del siglo XX e inicios de este nuevo milenio. Es desde este suelo histórico que procura descifrar y comprender las nuevas expresiones de la expansión inconcebible del capitalismo contemporáneo y su expresión particular en la actual sociedad brasileña. Convencida de que la complejidad de este proceso histórico demanda para su aprehensión e interpretación un riguroso y, a la vez, creativo retorno a los "clásicos", realiza su análisis desde Marx, enriqueciéndolo asiduamente con los aportes de Lenin y Gramsci, quienes, para la autora, además de sus excepcionales aportes, nos dejan como legado primordial el desafío de capturar el movimiento histórico del capital. Así, mostrando la fuerza y vigencia de conceptos medulares de las obras de estos autores, pero evitando su aplicación mecánica a los procesos actuales, Fontes los retoma como soporte fundamental de su reflexión, en interactivo diálogo con - no pocos — importantes autores contemporáneos (Harvey, Luxemburgo, Wallerstein, Wood, Quijano, Ruy Mauro Marini).

A partir de Lenin y su brillante aporte (basado en Wilferding) sobre las alteraciones substantivas que convirtieron el capitalismo competitivo en imperialismo (entre el siglo XIX y el XX), la autora centra su interés en el modo por el cual ocurren ese tipo de transformaciones, mediante las cuales el proceso de expansión del capital es capaz de - al impulsar su propia dinámica interna y por las contradicciones que potencia - modificarse al tiempo en que se perpetúa. Así, plantea como tesis que

\footnotetext{
* Profesora de la Universidad de Costa Rica. Estudiante de doctorado de Programa de Pós-Graduação em Serviço Social da Universidade do Estado de Rio de Janeiro (UERJ). Integrante del grupo de investigación del Centro de Estudios Octavio lanni (CEOI) da Faculdade de Serviço Social da UERJ. Endereço postal: CEOI, Rua São Francisco Xavier, 525, Bloco E, Sala 8031, Maracanã, Rio de Janeiro, Cep 20550-013. Email: ritameono@hotmail.com
} 
"El crecimiento del imperialismo, de forma no lineal y atravesado de luchas sociales y contradicciones, también condujo a un nuevo salto en la base de acumulación del capital, impulsado por un salto escalar en el proceso de expropiaciones sociales, primarias y secundarias, que altera cuantitativa y cualitativamente, una vez más, su tenor a lo largo de su expansión" (Fontes, 2010, p. 145-146).

Varias denominaciones son elaboradas para expresar la tragedia social de nuestro tiempo (Mandel, Capitalismo Tardío; Harvey, Nuevo Imperialismo; Chesnais, Mundialización del Capital) y, en aras de mejor caracterizarla, la autora propone la denominación capital-imperialismo, con la que busca reflejar la expansión de una forma de capitalismo que, impregnada de imperialismo, es una forma modificada de éste. Intenta recuperar "conceptos clásicos" que expresan determinaciones cruciales de ese proceso y enfatizan características exacerbadas por la expansión del capitalismo y su desdoblamiento imperialista, al tiempo que los revitaliza para el presente, como momento histórico que — siendo radicalmente diferente al período en que estos fueron elaborados - encarna la continuidad y profundización escandalosa de la misma dinámica expansiva del capital. Capital imperialismo permite "retroceder y avanzar", pues retoma de Marx las tendencias de expansión del capitalismo, incorpora las modificaciones que el imperialismo de Lenin introdujo y abarca características propias de la expansión imperialista bajo determinadas condiciones históricas.

Desde finales de la II Guerra Mundial, el imperialismo inició su conversión contradictoria para capital-imperialismo. Este nuevo padrón de concentración se derivó del impulso monopólico propiciado por la relación entre dos tipos específicos de grandes capitales: industrial y banquero, no obstante desembocó en la constitución de inmensos conglomerados multinacionales, que avanzaron en la dirección de una propiedad casi descarnada del capital, aproximándose más a la formulación marxista de concentración del capital bajo pura forma monetaria, de capital portador de intereses o del predominio de la pura propiedad de los recursos sociales de producción.

El complejo y turbulento período de la Post-II Guerra Mundial fue el terreno fértil para la expansión del imperialismo, pero bajo condiciones muy distintas a su perfil anterior. Sucedería una efectiva "unión íntima" entre capitales de cualquier origen, que da paso a la propiedad hiperconcentrada del capital monetario, que superó de hecho la propiedad inmediata de los medios de producción. El capital se convirtió el mismo en mercancía y, bajo la forma monetaria, sólo le interesa su reproducción ampliada. Ello redunda en que masas crecientemente concentradas de recursos imponen al conjunto de la vida social una acelerada, intensificada y devastadora extracción de plusvalía toda vez que el capital monetario (portador de intereses) no produce ampliada y regularmente plusvalía, y le es indispensable puncionar al capital funcional (capital que produce y extrae plusvalía).

La mega concentración del capital monetario favoreció, a su vez, el crecimiento exponencial de lo que Marx denominó capital ficticio; forma extremadamente compleja que utiliza recursos para los que no existen reservas o equivalente general (trabajo muerto pasado cristalizado en la forma de metal precioso o bajo la forma de moneda). El crédito, las letras de cambio, la deuda pública, son algunas de sus 
formas comunes. Tal proceso estimula, por su vez, todo tipo de fraudes y especulaciones, y en cuanto más se centraliza y concentra el capital, más se abren posibilidades para su uso fraudulento y especulativo.

Así se consolidaron las nuevas formas económicas y de políticas organizativas del capital-imperialismo. Por su particular funcionamiento predominantemente financiero y rentista, presenta como características esenciales el predominio del capital monetario, la dominación de la pura propiedad capitalista y el impulso avasallador expropiador; lo que resulta en la reproducción y propagación de la más perversa lógica de acumulación.

Según Marx, la expansión de las relaciones sociales capitalistas presuponen siempre sucesivas expropiaciones. De ahí, Fontes plantea como hipótesis central que "la expropiación es condición central para la implantación y expansión de la relación capital" (Fontes, 2010, p. 78) y propone una diferenciación entre expropiaciones primarias (aquellas originales, propias de las primeras transiciones para el capitalismo, limitadas a incidir sobre la tierra y los medios de producción: Inglaterra y Francia; Italia y Alemania; y EUA) y expropiaciones secundarias o disponibilizaciones (propias del capital-imperialismo; no suponen una pérdida de propiedad de los medios de producción o recursos sociales de producción, pues la mayoría de trabajadores urbanos ya no los detentan). Exhibiendo nuevos y variados formatos, suponen el desmantelamiento de derechos sociales y laborales.

Es desde esta perspectiva que Fontes aborda la comprensión de las nuevas características de las expropiaciones en el período del capital-imperialismo multinacionalizado; recolocando y preponderando la contradicción entre la salvaje expansión y concentración del capital-monetario hiperconcentrado y su correspondiente imposición de múltiples y, hasta entonces, impredecibles expropiaciones — primarias y secundarias - sobre el conjunto de la vida social, promoviendo intensa destrucción social, ambiental y humana, en aras de convertir — aunque desigualmente — todas las actividades humanas en trabajo; en formas de valorización del valor.

En esta lógica y, asumiendo ritmos diferenciados de extensión e intensidad según cada país y su capacidad de resistencia local, el capital-imperialismo se expande de forma tentacular, generalizando las relaciones capitalistas en el mundo. En el siglo XXI, escenario de profundas crisis, se gestan las condiciones y contradicciones que hacen emerger nuevas tendencias capital-imperialistas en países secundarios (en proceso análogo - aunque diferente por condiciones históricas - a la transición capitalista de los países retardatarios). Se ubican aquí los países denominados "emergentes", como Rusia, India, China, México, Corea y Brasil. Entre los elementos comunes que unifican ese conjunto dispar de países, la autora menciona: una fuerte base industrial al lado de una intensa concentración de capitales; su integración a los patrones internacionales predominantes; el bajo valor de la fuerza de trabajo en el mercado nacional en comparación con el mercado de países centrales; el adiestramiento y disponibilidad de mercado; y la extensa retirada o inexistencia de derechos.

En un breve y selectivo - pero para nada superficial — recorrido por la realidad histórica y social brasileña, Fontes muestra como en su país la profundización de las relaciones capitalistas - bajo el dominio del capital monetario - tienen 
como telón de fondo: *la dictadura civil-militar de 1964 y desde su seno un impactante impulso a la monopolización de la economía; *la implantación de un complejo sistema financiero; *la difusión del sistema de crédito que alteró hábitos de consumo popular; *expropiaciones y reexpropiaciones intensificadas; *una concentración exacerbada de capitales que se profundiza en los años 1990 (papel importante de fondos de pensión y fondos de inversión) y no se detiene ni por la apertura de mercados ni por las crisis del 2000 y del 2008; *ampliación del Estado con fuerte organización y difusión de aparatos privados de hegemonía de tipo empresarial, que objetivaba, mediante estrategias de persuasión, coerción, o represión selectiva, reducir la riqueza de los movimientos populares a formas de conciencia social de tipo corporativa y limitada; *aguerridas luchas populares que embargaron el país (especialmente durante los años 1970 y 1980), y, si bien lograron alterar formas políticas basadas en la truculencia, en adelante afrontarían la maquinaria pesada de concentración desenfrenada de capitales (severa investida patronal y empresarial ); *una alteración en la escala de concentración (a partir de la década de los 1990), potenciada tanto internamente, como por el crecimiento de Inversiones Directas Extranjeras, promovidas por privatizaciones y/o descentralizaciones trayendo consigo desnacionalización del sector productivo y pérdida de soberanía nacional; *comportamiento predatorio de empresas brasileñas (multinacionales y mega-conglomerados) a través de estrategias como: enseñoramiento de fuentes de materias primas y explotación de la fuerza de trabajo en otros países del continente, con políticas de alivio por goteo a determinadas presiones sociales internas. Con base en estas argumentaciones, Virginia Fontes propone como idea fuerza que "Brasil hoy integra el grupo desigual de países capital-imperialistas, en posición subalterna. Como el último de los primeros, en situación tensa e inestable, depende de una corrida alucinante de concentración de capitales que, a cada paso, encara crisis sociales dramáticas" (Fontes, 2010, p.359). Así, explicita la doble relación del capital-imperialismo brasileño - la de predominio, por un lado, y de subalternación, por otro derivado de las contradicciones y macrotendencias más amplias que configuran el capitalismo mundial; pero también resultante de las tradiciones prepotentes (autocráticas) que marcaron la historia de dominación burguesa de Brasil. "Tengo la plena convicción de que el capital-imperialismo es una tragedia para la humanidad y, en especial para ese rincón de la humanidad que es América latina y, en ella, para el pueblo brasileño. Procurar desvendar sus orígenes y modos de funcionamiento es el objetivo de este libro" (Fontes, 2010, p. 8). 


\section{Referências bibliográficas}

FONTES, Virginia. O Brasil e o capital; imperialismo, teoria e história. Rio de Janeiro: EPSJV/UFRJ, 2010.

Recebido em 14 de outubro de 2010.

Aceito para publicação em 29 de outubro de 2010. 